Title: Real-Time Visual Feedback of Airflow in Voice Training: Aerodynamic Properties of Two Flow Ball Devices

Author(s): Lã, Filipa M.B.; Wistbacka, Greta; Andrade, Pedro Amarante and Granqvist, Svante

Copyright, publisher and additional information:

(c) 2016. This manuscript version is made available under the CC-BY-NC-ND 4.0 license http://creativecommons.org/licenses/by-nc-nd/4.0/

DOI: http://doi.org/10.1016/j.jvoice.2016.09.024

Reference:

Lã, Filipa M.B.; Wistbacka, Greta; Andrade, Pedro Amarante and Granqvist, Svante (2016) Real-Time Visual Feedback of Airflow in Voice Training: Aerodynamic Properties of Two Flow Ball Devices. Journal of Voice. ISSN 08921997 


\section{Real-time visual feedback of airflow in voice training: aerodynamic properties of two flow ball devices}

Filipa M. B. Lã ${ }^{1,2}$, Greta Wistbacka ${ }^{3}$, Pedro Amarante Andrade ${ }^{4}$, Svante Granqvist ${ }^{5,6}$

\section{Authors:}

Filipa M. B. Lã ${ }^{1,2}$

${ }^{1}$ Center for Social Sciences, University of Coimbra, Portugal

${ }^{2}$ Institute of Interdisciplinary Research, University of Coimbra, Portugal

Greta Wistbacka ${ }^{3}$

${ }^{3}$ Faculty of Arts, Psychology and Theology, Abo Akademi University, Turku, Finland

Pedro Amarante Andrade ${ }^{4}$

${ }^{4}$ Faculty of Culture and Language Sciences, University of St Mark \& St. John, UK

Svante Granqvist ${ }^{5,6}$

${ }^{5}$ Division of Speech and Language Pathology, Department of Clinical Science, Intervention and Technology (CLINTEC), Karolinska Institutet (KI), Stockholm, Sweden

${ }^{6}$ Basic Science and Biomedicine, School of Technology and Health (STH), Royal Institute of Technology (KTH), Stockholm, Sweden

Running title: The Flow ball: aerodynamic characteristics

\section{Corresponding author:}

Filipa M. B. Lã

Postal address:

Centre for Social Sciences, University of Coimbra, Portugal

Institute for Interdisciplinary Research, University of Coimbra, Portugal

Largo D. Dinis

Apartado 3087

3000-995 Coimbra, Portugal

E-mail address: filipala@ces.uc.pt

Work telephone number: +351917646702 


\begin{abstract}
Objectives: Flow ball devices have been used as teaching tools to provide visual real-time feedback of airflow during singing. This study aims at exploring static back pressure and ball height as function of flow for two devices, marketed as flow ball and floating ball game.

Study design: Comparative descriptive study.

Method: A flow driven vocal tract simulator was used to investigate the aerodynamic properties of these two devices, testing them for four different ball sizes. The flow range investigated was between 0 and $0.5 \mathrm{~L} / \mathrm{s}$. Audio, flow, pressure and ball height were recorded. Results: The flow-pressure profiles for both tested devices were similar to those observed in previous studies on narrow tubes. For lifting the ball, both devices had a flow and a pressure threshold. The tested floating ball game required considerably higher back pressure for a given flow as compared with the flow ball.

Conclusion: Both tested devices have similar effects on back pressure as straws of 3.7 and $3.0 \mathrm{~mm}$ diameter, for the flow ball and the floating ball game, respectively. One might argue that both devices could be used as tools for practicing semi-occluded vocal tract exercises, with the additional benefit of providing real-time visual feedback of airflow during phonation. The flow threshold, combined with the flow feedback, would increase awareness of flow, rather than of pressure, during exercises using a flow ball device.
\end{abstract}

\title{
Keywords
}

Flow ball; Floating ball game; Back pressure; Airflow; Ball height; Real-time visual feedback of airflow; Semi-occluded vocal tract; Voice training 


\section{INTRODUCTION}

Phonation into narrow tubes has been substantially used in voice training. For example, resistant straws have been used to promote vocal economy, i.e. the production of normal vocal intensity with less mechanical trauma to the vocal folds' tissues. Previous investigations have suggested that such effect is achieved by engaging the vocal tract to transforming aerodynamic energy into acoustic energy by means of a back pressure created when phonating into a narrow tube ${ }^{1}$. Glass tubes submerged in water have also been applied in clinics to treat, for example, hyper nasality, hypo and hyper phonation and vocal nodules ${ }^{2}$. Although not yet described in the literature, there are other types of devices that can be explored as tools to train efficient voice use. For example, the flow ball (FB) is a device available for respiratory training. This type of device is claimed to be beneficial for respiratory training, especially for wind instrumentalists and singers ${ }^{\mathrm{a}, \mathrm{b}}$. Different devices can be found in the market. They contain a squared plastic tube that connects to a plastic basket with a narrow passage. The latter has a hole in the middle through which air passes when exhaling through the device, lifting a small polystyrene ball that comes with it. Other devices can be found at early learning centers, referred to as floating ball games (FBG) (see Figure 1).

\section{< Please insert Figure 1 about here>}

The use of the FB as a voice-training device was implemented for the first time in singing lessons by the author FL several years ago. This idea emerged from the fact that this device could facilitate the visualization of flow via inspecting the ball height when phonating. Simultaneously, it also provides the potential effect of a semi-occlusion of the vocal tract. Students practicing with it realize the easiness of phonation when changing airflow according to the frequency and the intensity of each note in an exercise or when singing a musical phrase. This visualization of breath management (i.e. appoggio) ${ }^{3}$ is of paramount importance for a classical trained singing to avoid timbre changes associated with pressed phonation, especially when singing fortissimo. Classically trained singers are expected to be able to change frequency and intensity of tones keeping the same phonation mode. Pressed phonation involves a high adduction force and, consequently, low flow amplitudes, ending in greater vocal effort when compared with flow phonation ${ }^{4}$. The latter promotes vocal economy as an increased acoustic output is achieved with lower subglottal pressure and a more moderate adduction ${ }^{4}$. Adding to FL's anecdotal experience results of a preliminary investigation on the effects of FB use on voice revealed a decrease in contact quotient immediately after its use for professional singers performing a messa di voce at different pitches ${ }^{5}$. Positive experiences have been also reported by singing students using the FB as a respiratory exercising tool and as a phonatory training device ${ }^{5}$. Instructions on its use include: i) holding the proximal end firmly between the lips while phonating into the tube; ii) maintaining control of breath and phonation so that the ball is kept in the airstream while phonating. This is possible as the ball stays near the center of the airstream due to the pressure being the lowest where the air speed is the highest (i.e. Bernoulli effect).

The results of previous studies suggest that the provision of meaningful and quantitative feedback in a singing lesson encourages the development of consistent subsequent repetitions of the same neuromotor behaviour, i.e. "Knowledge of Results"6. Misunderstanding of the information prior to and after providing feedback might be avoided if the feedback is immediate $^{6}$. Moreover, phonation habits seem to change quicker in a singing lesson when

\footnotetext{
${ }^{\mathrm{a}} \mathrm{http}: / / \mathrm{www} \cdot$ thomann.de/intl/thomann flowball.htm?sid=2df448726396b313dfcd22787ec1f2d4 [accessed 1207-2016, 16: 51]

${ }^{\mathrm{b}}$ http://www.powerbreathe.com/flowball-blue [accessed 12-07-2016, 16:51]
} 
using visual feedback (e.g. electrolaryngographic displays) together with verbal instructions ${ }^{7}$, ${ }^{8}$. Visual feedback also assists in the development of student's independence, self-correction, self-evaluation and appraisal skills, promoting cognitive and associative stages of learning 9 .

Finally, the FB might also add the benefits of a semi-occluded vocal tract, as phonation into a narrow tube is required. As suggested earlier, phonation into narrow tubes increases the static back pressure $\left(P_{b a c k}\right)$ (i.e. analogous to intraoral pressure) in the vocal tract for a given flow ${ }^{10}$. These authors measured the back pressure - flow $\left(P_{\text {back }}-U\right)$ relationship for different tube lengths and diameters commonly used in voice training, concluding that a change in tube diameter would affect the flow resistance more than a corresponding relative change in tube length. This has later been confirmed by Smith and Titze (article in press), who based on flow theory and empirical data suggested two models for the pressure-flow relationship ${ }^{11}$.

This paper aims at exploring the physical properties of two different flow ball devices, the FB and the FBG, in terms of relationships between $P_{\text {back }}$, air flow $(U)$ and ball height $\left(h_{B}\right)$.

\section{METHOD}

\section{The flow ball (FB)}

For the purposes of this experiment, 2 flow ball devices were investigated. The first device, $\mathrm{FB}$, consisted of a $140 \mathrm{~mm}$ long tube with a rectangular cross section of 7 by $10 \mathrm{~mm}$. A basket with a narrow, upward facing opening of $3.9 \mathrm{~mm}$ diameter ${ }^{12}$ was attached to the tube. The device was supplied with a polystyrene ball of Ø $29 \mathrm{~mm}$ (see Figure 2).

\section{< Please insert Figure 2 about here >}

\section{The floating ball game (FBG)}

Another device was tested, the FBG made of wood. With a total length of $147 \mathrm{~mm}$, this device had an inner longitudinal tube with $\emptyset 7 \mathrm{~mm}$. At a distance of $95 \mathrm{~mm}$ along the length of this tube, a smaller tube with $20 \mathrm{~mm}$ length and $3.5 \mathrm{~mm}$ inner $\emptyset$ was perpendicular inserted. In this particular tested specimen, the smaller tube was inserted deep into the tunnel so that it created a narrow passage between the two attached tubes. On the wood shaft, there was a ring also made of wood where the ball was placed. The FBG was provided by a polystyrene ball of $\varnothing 34.5 \mathrm{~mm}$ (see Figure 3).

\section{< Please insert Figure 3 about here >}

\section{Experimental setting}

The $P_{b a c k}-U$ characteristics of these flow ball devices were measured with a flow driven vocal tract simulator similar to the one used in a previous study ${ }^{6}$. A ruler was kept next to the devices during video recordings in order to calibrate $h_{B}$. An air pressure of approximately 100 $\mathrm{kPa}$ was supplied from a pressurized air cylinder to a mass flow controller (Alicat Scientific model MCR-50SLPM-TFT), connected to a $60 \mathrm{ml}$ size syringe set with an inner cavity volume of $36 \mathrm{ml}^{6}$. A pressure transducer (8-SOP MPXV7007DP-ND Freescale Semiconductor, Petaling Jaya Malaysia) was attached to the syringe and the flow ball device was placed at the end, sealed with plasticine. A representation of this experimental setting is shown in Figure 4.

\section{$<$ Please insert Figure 4 about here >}

\section{Recordings and analysis}

The experiments were recorded using a Canon 700D digital camcorder with a Canon EF-S $18-200 \mathrm{~mm}$ lens. Video recordings of $h_{B}$ were carried out at a rate of 25 frames per second, at 
a resolution of 1920 by 1088 pixels. In order to determine the range for $h_{B}$ to be recorded, typical singing exercises with the FB device were performed by the author FL prior to the experiments. A range of $h_{B}$ of $2-7 \mathrm{~cm}$ was used to determine the range of $U$ needed.

Audio, $U$ and $P_{\text {back }}$ signals were recorded at sampling rate of $16 \mathrm{kHz}$ using the Soundswell signal workstation and a DSP board allowing DC input. The transducer for $P_{\text {back }}$ was calibrated using a U-tube manometer. A visible clap of the hands was used to synchronize audio, $U$ and $P_{b a c k}$ with the video. The audio was also recorded for documentation purposes. Based on the $h_{B}$ observed in the singing exercises, a $U$ range of 0 to $0.5 \mathrm{~L} / \mathrm{s}$ was used. This was supplied over $90 \mathrm{~s}$ by the custom made software Mjau (by author SG).

The $h_{B}$ was measured from the digital video recording using a Matlab ${ }^{\mathrm{TM}}$ script. An area of the video containing only the ball and the neutral background was selected. The top edge of the ball was detected by looking for the increased pixel brightness caused by the white ball. Also, two positions on the ruler were associated with pixels in the video, enabling absolute calibration of $h_{B}$. This procedure resulted in 25 measurements per second of $h_{B}$.

The $P_{\text {back }}$ and $U$ signals were calibrated and down-sampled to $25 \mathrm{~Hz}$ using the custom made Sopran Software (by author SG) and synchronized with the $h_{B}$ measurement. Thus, the experiment resulted in a data file at $25 \mathrm{~Hz}$ sampling rate, with channels containing $U, P_{\text {back }}$ and $h_{B}$. The signals were low-pass filtered to smooth the graphs plotted using Matlab. This procedure was performed for the recordings of the two devices tested with four balls of different sizes (see Table 1), as well as for recordings made without the balls. When recording the $P_{\text {back }}-U$ characteristics without the ball, the experiments were not video recorded.

Although the balls that originally come with the devices are similar in shape and size, four different ball sizes were tested as they might be replaced by other sizes when the original ones are damaged or lost. In addition, singing teachers might want to change $P_{b a c k}$ and $U$ relationships using the same device, thus using different ball sizes to achieve such combinations.

\section{<Please insert Table 1 about here>}

\section{Straw dimension adaptations}

The $P_{\text {back }}-U$ relationship appeared to be similar to that of a straw, thus adaptations to the Smith \& Titze's basic flow model (see equation 1) and modified flow model (see equation 2 ) were attempted to compute equivalent straw diameters and lengths. For these adaptations, both the solver add-in in Microsoft Excel (2010) and a brute force method implemented in Matlab were tested.

$$
\begin{aligned}
& p_{\text {back }}=\left(1.446 \cdot 10^{-6} \cdot \frac{\rho}{D^{4}}\right) U^{2}+\left(0.1752 \cdot \frac{\mu L}{D^{4}}\right) U \\
& p_{\text {back }}=\left(3.7631 \cdot 10^{-7} \cdot \frac{L}{D^{4.4997}}+1.0268 \cdot 10^{-6} \cdot \frac{1}{D^{4.0416}}\right) U^{2}+\left(3.9913 \cdot 10^{-9} \cdot \frac{L}{D^{5.0089}}+\right. \\
& \left.8.0169 \cdot 10^{-7} \cdot \frac{1}{D^{3.7696}}\right) U
\end{aligned}
$$

where $P_{\text {back }}$ is the flow-dependent back pressure from the tube in $\mathrm{Pa}, \rho$ is the density of air $\left(1.225 \mathrm{~kg} / \mathrm{m}^{3}\right), D$ is the tube diameter in $\mathrm{m}, U$ is the flow in $\mathrm{L} / \mathrm{s}, \mu$ is the dynamic viscosity of air $\left(1.983 \cdot 10^{-5} \mathrm{~Pa} \cdot \mathrm{s}\right)$ and $L$ is the length of the tube in $\mathrm{m}$.

\section{RESULTS}

\section{The FB}


Figure 5 shows the results for the FB with all balls tested. A $P_{b a c k}-U$ relationship similar to that of the FB without the ball was found when adding all balls, except for the range between 0 to $0.1 \mathrm{~L} / \mathrm{s}$ for the smallest ball ${ }^{13}$. With respect to this ball, it stayed in the basket covering the hole until $0.1 \mathrm{~L} / \mathrm{s}$ where it started to bounce. At $0.2 \mathrm{~L} / \mathrm{s}$ it started to lift off. For higher flows, the $h_{B}$ seemed to increase linearly with $U$, reaching $10 \mathrm{~cm}$ at $0.4 \mathrm{~L} / \mathrm{s}$. Another way of looking at the results is considering how the $h_{B}$ depends on the $P_{b a c k}$; about $5 \mathrm{cmH}_{2} \mathrm{O}$ was required for the ball to lift off. However, the relationship between $h_{B}$ and $P_{b a c k}$ did not appear to be linear.

\section{< Please insert Figure 5 about here >}

For ball \#2, the results were almost identical, the main difference being the absence of the hump in the $P_{b a c k}-U$ profile. For the considerably larger ball, ball \#3, the threshold for lift off was increased to about $0.3 \mathrm{~L} / \mathrm{s}$ and $10 \mathrm{cmH}_{2} \mathrm{O}$. For ball \#4, lift off occurred beyond $0.5 \mathrm{~L} / \mathrm{s}$ and a $P_{\text {back }}$ of about $25 \mathrm{cmH}_{2} \mathrm{O}$.

\section{The FBG}

Figure 6 shows the results for all balls tested using the FBG. No humps were found in the $P_{\text {back }}-U$ profile for this device; the balls never covered the hole.

Considering ball \#1, the $h_{B}$ revealed a similar behavior as to the FB, but a slightly higher $U$ was required for lift off: about $0.25 \mathrm{~L} / \mathrm{s}$. For higher $U$, the $h_{B}$ appeared to relate linearly with increasing $U$. However, the $P_{\text {back }}$ required for lift off was about $20 \mathrm{cmH}_{2} \mathrm{O}$, hence 4 times higher than for the FB.

Ball \#2 required a slightly higher $U$ for lift off as compared to ball \#1: about $0.27 \mathrm{~L} / \mathrm{s}$. A linear relationship between $U$ and $h_{B}$ was still observed. The $P_{b a c k}-h_{B}$ relationship for this ball revealed a threshold $P_{\text {back }}$ of about $20 \mathrm{cmH}_{2} \mathrm{O}$ for lift off.

Ball \#3 required high $U$ and $P_{\text {back }}$ for lift off: $>0.4 \mathrm{~L} / \mathrm{s}$ and $50 \mathrm{cmH}_{2} \mathrm{O}$.

Ball \#4 did not lift off for the flows used in this study.

\section{< Please insert Figure 6 about here >}

While carrying out the recordings, a bouncing of the ball in the airstream was noticed. When inspecting these oscillations closely, it was found that they occurred at a frequency of 1.5 to 2 $\mathrm{Hz}$, as exemplified in Figure 7.

\section{$<$ Please insert Figure 7 about here >}

\section{Straw dimension adaptations}

When adapting the recorded data to the modified flow model provided by Smith \& Titze (in Press), the Excel solver method did not converge to an optimum. The brute force method implemented in Matlab found an optimum match for a straw with a negative length, which is of course unrealistic. Using the basic flow model, Excel and Matlab provided nearly identical optima and resulted in a positive straw length. The predictions of $P_{\text {back }}$ by the basic model matched measured data with an average error of 0.14 and of $0.17 \mathrm{cmH}_{2} \mathrm{O}$ for the $\mathrm{FB}$ and $\mathrm{FBG}$, respectively (see Table 2).

\section{$<$ Please insert Table 2>}

Figure 8 compares the measured results for $P_{b a c k}-U$ relationships for both FB and FBG with no balls; the predictions were made applying the basic flow model. 


\section{DISCUSSION}

The present investigation aimed at describing the physical properties of a device recently implemented in singing lessons. A FB and a FBG with four ball sizes were compared. Relationships between $P_{b a c k}, U$ and $h_{B}$ were investigated.

Both devices showed similar $P_{\text {back }}-U$ profiles to that of a straw, although with different dimensions. Both FB and FBG had thresholds for the ball to lift off regarding $U$ and $P_{\text {back }}$. The $U$ thresholds were similar, but the $P_{\text {back }}$ threshold for the FBG was considerably higher than for the FB. The FBG had a narrower opening, hence a $P_{b a c k}-U$ profile that resembles a considerably thinner straw. The FBG device provides an almost 2.6 times higher $P_{\text {back }}$ as compared to the FB for the same $U$.

Previous studies on the effects of phonating into a glass tube and a stirring straw have found a decreased glottal adduction, presumably as a direct physiological result of the increased pressure in the vocal tract ${ }^{14}$. Increasing the oral pressure, maintaining subglottal pressure $\left(P_{s u b}\right)$ and glottal resistance, would reduce the transglottal pressure and $U$. This would be true both for straws and for both FB and FBG, due to their similar $P_{b a c k}-U$ profiles. However, the results of this and previous investigations ${ }^{10}$ suggest that even small changes in tube diameter might have a considerable effect on $P_{b a c k}$, emphasizing the need for awareness of the physiological effects of $P_{b a c k}$ during voice training.

The predictions of tube lengths based on the two flow models by Smith \& Titze (in press) varied considerably ${ }^{11}$. It appears as while the models work well for predicting a $P_{b a c k}$ from tube dimensions, they are numerically ill-conditioned when applied backwards, i.e. when trying to predict tubes length from $P_{b a c k}$ data. It has been shown that a change in relative tube length affects the $P_{b a c k}$ to a much lesser degree than the corresponding relative change in tube diameter ${ }^{10}$; a relatively large change in tube length only affects the $P_{\text {back }}$ slightly. When the $P_{\text {back }}-U$ relationship is applied backwards, this has the effect that a slight change in $P_{\text {back }}$ data may lead to a large change in the estimation of the tube length. With that in mind, the equivalent tube lengths found in this paper should be considered as rough estimations. It is true that a straw with the suggested dimensions will have a similar back pressure - flow profile as the flow ball devices, but other tube dimensions may also have similar profiles.

A finding from the video recordings was that the ball occasionally started to oscillate, sometimes at an amplitude so high that it fell out of the air stream. Looking closer at these oscillations, they occurred in the frequency range between $1-2 \mathrm{~Hz}$. Thus, it appears as if the device with the ball in the air has similarities with a resonant system with a resonant frequency near $1-2 \mathrm{~Hz}$. If the singer would provide a flow with oscillations in this frequency range, corresponding to $60-120 \mathrm{BPM}$, these oscillations would be amplified and the ball could fall out of the airstream. One could argue that this property of the device would promote the use of a steady flow with a more legato-like phonation, e.g. during messa di voice or arpeggio exercises.

The $h_{B}$ provides visual feedback of the amount of airflow used. Thus, a flow ball device could be used as a $U$ meter. Different phonation types could be visualized through the amount of $U$ the singer would apply. The $h_{B}$ range of $0-10 \mathrm{~cm}$ for the FB would correspond to $U$ of $0.2-0.4 \mathrm{~L} / \mathrm{s}$. It could be speculated what behavioral changes this might lead to. At a glottal level, high flow and low transglottal pressure corresponds to a low flow resistance, i.e. a small amount of adduction. Using the FB, the singer could choose between applying a high $P_{s u b}$ or using less adduction to achieve a sufficiently high $U$. The lift of the ball and its maintenance in the air stream could therefore encourage use of less adduction, promoting the awareness that pressure and flow are different dimensions that can be changed separately. From a 
pedagogical point of view, this seems also worthwhile because the student could be encouraged to explore the sensation of achieving maximum flow with a complete glottal closure. This type of phonation, i.e. flow phonation, has been associated with an improved vocal function, as it requires lower $P_{s u b}$ and moderate degree of adduction force ${ }^{4,15}$.

Moreover, the combination of visual feedback with verbal instructions can assist both teacher and student in achieving a common vocabulary voided of multiple translations of sound quality into words ${ }^{16,17}$. Additionally, the different types of learners in a singing lesson (i.e. intellectual, aural, kinesthetic and visual) call for the need for applying different types of feedback and a teaching model distant from the "one model fits all"18.

In summary, the results here discussed confirm that flow ball devices have a similar $P_{\text {back }}-$ $U$ profile as narrow tubes. However, when applied to singing lessons, the flow ball device provides visual real-time feedback of airflow during phonation.

\section{CONCLUSIONS}

The results of this study suggest that flow ball devices seem to be useful pedagogical tools for singing practice. On the one hand, they provide real-time visual feedback of airflow. The ball height can be used as an indication of the amount of airflow that is being used, an essential element in singing training. Flow phonation is the most advantageous phonation type in terms of ease of phonation, thus being emphasized when training voices ${ }^{19}$. In addition, as previous results have suggested, visual feedback (when combined with verbal feedback), might have a significant positive effect on student's development. It is however important to emphasize that different flow ball devices might have different lift-off, flow/pressures, and aerodynamic properties. Therefore, it seems worthwhile to assess these characteristics before using them and to make sure that they correspond to the needs of the intended exercises.

\section{REFERENCES}

1. Titze IR. Voice Training and Therapy With a Semi-Occluded Vocal Tract: Rationale and Scientific Underpinnings. Journal of Speech, Language, and Hearing Research. 2006;49:448-459.

2. Simberg S, Laine A. The resonance tube method in voice therapy: Description and practical implementations. Logopedics Phoniatrics Vocology. 2007;32:165-170.

3. Lã FMB, Gill BP. Physiology and its impact on the performance of singing. In: Welch G, Howard D, Nix J, eds. The Oxford Handbook of Singing. Vol OXFORD HANDBOOKS ONLINE (http://www.oxfordhandbooks.com). Oxford: Oxford University Press; 2015:1-19.

4. Sundberg J. The science of the singing voice. Illinois: Northern Illinois University Press; 1987.

5. Lã FMB, Granqvist S. Semi-Occluded Vocal Tract Gestures with Real-Time Feedback of Airflow:

Impacts on Voice During Vocal Training. 43rd Voice Foundation Annual Symposium: Care of the Professional Voice. Philadelphia, USA2014.

6. Welch GF, Howard DM, Himonides E, Bereton J. Real-time feedback in the singing studio: na innovatory action-research project using new voice technology. Music Education Research. 2005;7:225-249.

7. Lã FMB. Teaching Singing and Technology. In: Basa KS, ed. Aspects of Singing II Unit in Understanding - Diversity in Aesthetics. . Nürnberg Vox Humana; 2012:88109.

8. Herbst CT, Howard DM, Schlömicher-Thier J. Using Electroglottographic Real-Time Feedback to Control Posterior Glottal Adduction during Phonation. Journal of Voice. 2010;24:72-85. 
9. Lennon M, Reed G. Instrumental and vocal teacher education: competences, roles and curricula. Music Education Research. 2012;14:285-308.

10. Amarante Andrade P, Wistbacka G, Larsson H, et al. The Flow and Pressure Relationships in Different Tubes Commonly Used for Semi-Occluded Vocal Tract Exercises. Journal of Voice. 2016;30:36-41.

11. Smith SL, Titze IR. Characterization of Flow-resistant Tubes Used for Semi-occluded Vocal Tract Voice Training and Therapy. Journal of Voice. In Press.

12. Jørgenson H. Strategies for individual practice. In: Williamon A, ed. Musical Excellence. Oxford: Oxford University Press; 2004:85-104.

13.

http://www.thomann.de/intl/thomann_flowball.htm?sid=2df448726396b313df cd22787ec1f2d4. 2016.

14. Guzman M, Laukkanenm AM, Krupa P, Horácek J, Svec JG. Vocal Tract and Glottal Function During and After Vocal Exercising With Resonance Tube and Straw. Journal of Voice. 2013;27.

15. Gauffin J, Sundberg J. Spectral correlates of glottal voice source waveform characteristics. Journal of Speech and Hearing Researcg. 1989;32:556-565.

16. Nair G. Voice - Tradition and Technology: a state-of-the-art studio. San Diego: Singular Publishing Group; 1999.

17. Lã FMB. Learning to be a professional singer. In: Papageorgi IaW, G.F. (Eds.) ed. Advanced Musical Performance: Investigations in Higher Education Learning. . Aldershot: SEMPRE Studies in the Psychology of Music, Ashgate Press; 2014:265287.

18. McCoy S. Your Voice: An Inside View - Multimedia Voice Science and Pedagogy. Princeton: Inside View Press; 2004.

19. Gartner-Schmidt J. Flow Phonation. In: Behrman A, Haskell J, eds. Exercises for Voice Therapy. San Diego: Plural Publishing; 2008:24-26. 
Figure 1. The two flow ball devices tested in this study: the floating ball game model (top) and the flow ball model (bottom).

Figure 2. The flow ball device (FB) and its constituting parts (by PowerBreath()).

Figure 3. The gloating ball game device (FBG) and its constituting parts. The narrow constriction at the connection between the two tubes can be visualized by a strong light from above (upper left image).

Figure 4. Schematic representation of the experimental set up.

Figure 5. Back pressure and flow relationship for the flow ball (FB) and floating ball game (FBG) devices (solid lines) and for the adaptation of the basic flow model to the data represented in Table 2 (dashed lines).

Figure 6. Results for the flow ball device (FB). The following relationships are represented for the 4 tested ball sizes: back pressure and flow (left panel); ball height and flow (middle panel); back pressure and ball height (right panel).

Figure 7. Results for the floating ball game device (FBG). The following relationships are represented for the 4 tested ball sizes: back pressure and flow (left panel); ball height and flow (middle panel); back pressure and ball height (right panel).

Figure 8. Graphic representation of the ball height as a function of time during one recording of the flow ball device (FB) with its supplied ball (i.e. ball \#1). At approximately $42 \mathrm{~s}$, the ball height oscillates at a frequency of $1.6 \mathrm{~Hz}$. 
Table 1. Balls' sizes and weights tested in this study. Balls number 1 and 2 were supplied with the flow ball (FB) and the floating ball game (FBG), respectively.

\begin{tabular}{cccc}
\hline Ball number & Diameter [mm] & Weight [g] & Density [g/cm3] \\
\hline 1 & 29.0 & 0.304 & 0.0461 \\
2 & 34.5 & 0.347 & 0.0371 \\
3 & 37.2 & 0.652 & 0.0600 \\
4 & 48.1 & 1.595 & 0.0878 \\
\hline
\end{tabular}

Table 2. Estimated diameters and lengths for straws with equivalent back pressure and flow profiles to the ones found for the flow ball (FB) and the floating ball game (FBG) devices, applying the basic and the modified flow models by Smith \& Titze (in Press). Note the unrealistic negative lengths that resulted from applying the modified flow model.

\begin{tabular}{ccccc}
\hline \multirow{2}{*}{ Device } & \multicolumn{2}{c}{ Basic flow model } & \multicolumn{2}{c}{ Modified flow model } \\
\cline { 2 - 5 } & Diameter $[\mathrm{mm}]$ & Length [mm] & Diameter [mm] & Length ]mm] \\
FB & 3.7 & 31 & 2.7 & -112 \\
FBG & 3.0 & 33 & 2.3 & -85 \\
\hline
\end{tabular}

